\title{
Das Gottesbild in der Offenbarung des Johannes
}

\author{
Hrsg. v. Martin Stowasser
}

Das Gottesbild

in der Offenbarung

des Johannes

Herausgegeben von

MARTIN STOWASSER

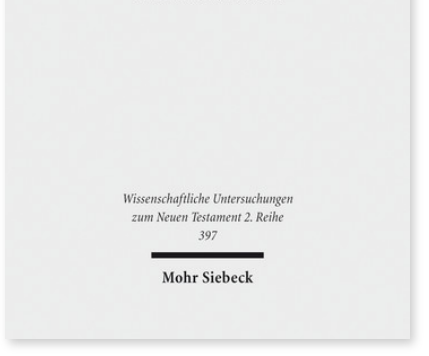

2015. VIII, 256 Seiten. WUNT II 397

ISBN 978-3-16-153972-5

DOI 10.1628/978-3-16-153972-5

eBook PDF 104,00€

ISBN 978-3-16-153449-2

fadengeheftete Broschur 104,00 €
Das Gottesbild der Offenbarung des Johannes erweist sich bei näherem Hinsehen als ausgesprochen facettenreich und religionshistorisch wie theologisch komplex. Der Sammelband geht auf eine Tagung an der Universität Wien zurück und beleuchtet die intertextuellen Bezüge zum Alten Testament, die Vernetzungen mit der zeitgenössischen römisch-

hellenistischen Leitkultur und die staats- wie sozialkritische Seite dieses Gottesbildes. Mit der Frage nach wesensmäßiger oder funktionaler Dimension der Christologie sowie den auf Christus übertragenen Gottesepitheta wird die monotheistische Verankerung des Gottesbildes der Johannesoffenbarung in den Blick genommen und durch Gemeinsamkeiten und Unterschiede zu Gottesaussagen im Johannesevangelium ergänzt. Die Perspektive der Wirkungsgeschichte in der modernen Literatur rundet den Band ab.

\section{Inhaltsübersicht}

Beate Kowalski: Gottesbilder in Offb 21,1-8. Alttestamentliche Vernetzungen - Martin Karrer: Das Gottesbild der Offenbarung vor hellenistisch-frühkaiserzeitlichem Hintergrund - Michael Labahn: Der Menschensohngleiche als Gottes Richter und Gottes Krieger in Offb 1,9-20. Christologie zwischen Schriftrezeption, griechisch-römischer Vorstellungswelt und christlicher Deutung - Klaus Wengst: Protest als Zeugnis und Widerspruch. Soziale und politische Aspekte im Gottesbild der Offenbarung - Konrad Huber: »Gott bete an!« (Offb 19,10; 22,9). Christusbild und Gottesbild der Johannesoffenbarung im Spannungsfeld von wesensmäßiger und funktionaler Einheit und Differenz - Martin Stowasser: Gottesepitheta als Christusepitheta.

Überlegungen zur Gottheit Gottes in der Offenbarung des Johannes - Martin Hasitschka: Zeugnis für Gott in der Offenbarung des Johannes und im Johannesevangelium Gemeinsamkeiten und Unterschiede - Rita Müller-Fieberg: »Nah ist und schwer zu fassen der Gott...« (F. Hölderlin). Das Gottesbild der Johannesoffenbarung in ausgesuchten Beispielen literarischer Rezeption

Martin Stowasser Geboren 1959; 1978-83 Studium der Kath. Theologie in Rom; 1990 Promotion in Wien; 2001 Habilitation; seit 2001 Ao. Univ.-Prof. für Neutestamentliche Bibelwissenschaft an der Kath.-Theol. Fakultät der Universität Wien.

Jetzt bestellen:

https://mohrsiebeck.com/buch/das-gottesbild-in-der-offenbarung-des-johannes-9783161539725?no_cache=1 order@mohrsiebeck.com

Telefon: $+49(0) 7071-923-17$

Telefax: +49 (0)7071-51104 